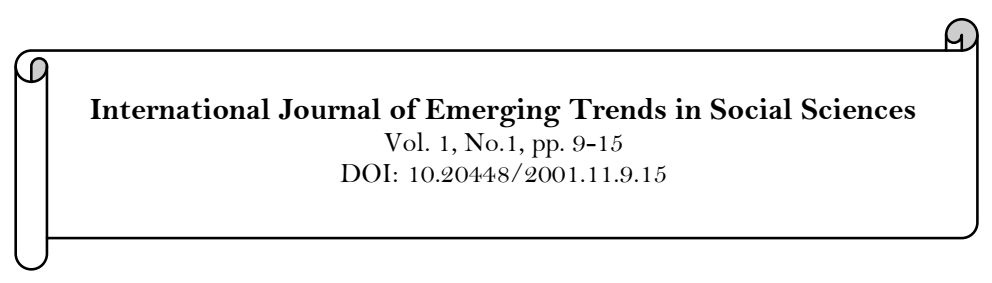

\title{
Challenges and Prospects of Applying Scientific Methods in Sociological and Policy Investigation
}

\author{
Bassey, Antigha Okon ${ }^{1}$ \\ Abang, Thelma Aya ${ }^{2}$ \\ IJI, Mary Eru ${ }^{3}$
}

${ }^{1,2}$ Lecturer, Department of Sociology University of Calabar, Calabar, C.R.S., Nigeria.

${ }^{3}$ Assistant Research Fellow, Institute of Public Policy and Administration University of Calabar, Calabar, C.R.S., Nigeria.

\begin{tabular}{|c|c|}
\hline Abstract & \\
\hline $\begin{array}{l}\text { The paper examines sociological and policy investigations, in terms } \\
\text { of its method of inquiry and the possibility of applying scientific } \\
\text { methods. Major tools, techniques and methods of science were } \\
\text { highlighted and discussed showing their extent of application in } \\
\text { Sociology and Policy Studies. The paper maintains the stand that } \\
\text { both disciplines as Social Sciences utilized scientific methods and } \\
\text { identified measurement difficulties, subjectivity and methodological } \\
\text { crises as their major limitations as sciences. It concluded that though } \\
\text { theory building and experimentation are not possible in social } \\
\text { sciences, the adaptation of observation, quantification, identification } \\
\text { of problem, hypothesis formulation and testing, position both } \\
\text { Sociology and Policy Study as sciences. It is expected that with the } \\
\text { passage of time, Sociology and Policy Studies will reveal their full } \\
\text { scientific attributes. It was recommended that scientific methods } \\
\text { should be explored and utilized in all social sciences extensively. }\end{array}$ & $\begin{array}{l}\text { Keywords: } \\
\text { Challenges } \\
\text { Prospects } \\
\text { Scientific methods } \\
\text { Sociology } \\
\text { Policy } \\
\text { Investigation. }\end{array}$ \\
\hline
\end{tabular}

\section{Introduction}

Sociology is universally acclaimed as a core social science discipline. This scientific acclamation is accorded sociology in view of application and continuous adaptation to basic scientific requirements in its investigation, as well as utilization of tools and methods of science in the discovery of knowledge and theory construction. The process of evolving the science of sociology, if it has really been attained, has not been an easy one. As revealed by the work of such eminent scientists like Adedokun (1999). Anon-core (substantive) science like sociology should be critically examined to prove or otherwise its claim as a science. Policy Studies is a multi-disciplinary area, which involves sociology, political science, law and economics. Policy studies like Sociology, is within the confinement of Social Sciences. It is in this regard that application of scientific investigation tools is examined in policy studies, side by side Sociology.

Therefore, the central problematique necessitating this scholarly presentation, is to provide a critical analysis of the level to which scientific methods and tools can be applied in sociological and policy research. This essay is specifically aimedat providing extensive description of the concept of science, and the method of science. It will also give a basic guide to understanding the discipline of sociology, as well as, attempting to provide a place for classification of sociology among the sciences. This paper is very significant, as it will aid the understanding of the major concepts of discourse already highlighted, as well as add to the existing volume of scholarly work and literature on the discovery of the "Science of Sociology and Policy Analysis".

\section{Conceptualization}

In an academic exercise such as this, it is appropriate to commence detail analysis of concepts and variables by providing definitions. In this regard the following are considered; Science, Sociology, Scientific methods, Application, Investigation and Research.

Science is simply a systematized body of knowledge acquired through logical process. Gonser, Grant, Meechan, Muir, and Wiedersich (1965) defined science as "the production of systematic explanations, based upon empirical data joined logically to form regular patterns. Cohen and Manion (1980) further posited that science is "a way of comprehending the world, as well as a means of explanation and understanding, of prediction and control."Auguste Comte in Anikpo (1986) sees sociology as the study of human beings as they 
are organised in society. Generally, sociology is defined as the study of man in society or the science of society. The full import of this definition begins to unfold when society is explained as the network of interrelationships between people, which incorporates everything which human beings do in a group.

According to Obasi (1999) scientific method involves a logical, empirical, systematic and integrated process of collecting and analysing data with the aim of providing, explanation and prediction. In this study, Application refers to the way a particular thing is in use on something else. Here the application or usage of scientific method in sociology. Investigation implies an attempt to find out the reasons for the occurrence of something. When the object of investigation involves scholarly inquiry it becomes research. Ehon (1998) defined research as the process of systematic inquiry by which we increase our knowledge of how things are, why things are the way they are and how they might be changed." Sociological investigation refers to the ways sociologists inquire about occurrences in society, to discover causes, their consequences and possible solutions to problems associated with social phenomenon occurring in society. Policy involves decisions about what is to be done within specified period of time and the allocation of resources to ensure that the objectives of such decisions are attainable. Sociologists are preoccupied with addressing social problems in society, which policy provides, presenting a clear link between policy studies and sociology.

\subsection{Analysis of Scientific Methods}

Drawing from the definition of scientific method by Obasi (1999) there are five major characteristic features of scientific method of inquiry as follows: there is the assumption of some form of determination or "law of universal causation." This implies that scientists assume that things do not just occur accidentally, but that events have causes, that events are determined by other circumstances.

The second major characteristic of the scientific method is its empirical basis. This includes an observational foundation, and the value-free nature of science. Alternatively, the empirical basis of science means that investigations are focused on concrete facts or realities which are amenable to verification by observation. The five major component of empiricism according to Mouly (1978) are; experience, classification, quantification, discovery of relationships and approximation to the truth.

The third characteristics of the scientific method is its systematic nature. Science follows a logical or orderly process in its investigation, presentation and analysis of data. In other words, science is theoryoriented and theory- directed. The objectives of science are to formulate and verify empirical generalizations, develop systematic theory, and finally explain and predict. Another characteristic of the scientific method is its imperative demand for objectivity. Scientists are expected to report, describe, analyse and explain facts as they are, without bias. Scientific method is cumulative in the sense that it builds on existing body of knowledge and at the same time aims at expanding its frontiers.

Other than the scientific method, there are other four methods of seeking knowledge, which according to Anikpo (1986) are: sense experience, reasoning, intuition, revelation and faith. To Obasi (1999) knowledge acquired through experience, faith and reason may be scientific or unscientific. Scientific knowledge is gained through the adaptation of scientific procedures as embodied in scientific method. When considering the definition of science, it moves synonymously with investigation or research, which is the systematic, controlled, empirical and critical investigation of hypothetical propositions about the presumed relations among natural phenomena, but in the context of sociology, we consider social phenomena.

According to Werkmeisler (1996) scientific methods are inseparably connected with the aims and purpose of science. The aim of science, however, may be differently defined, it may be a complete description of reality, or an explanation of the processes and phenomena of nature. Description generally meant a simple enumerative account of the observable features or qualities of individual things, acts or events. An explanation on the other hand, is an attempt to account for the facts, to show "why they are", and "what they are."

Scholars in the field of social sciences all agreed on the procedures and the sequence of activities involved in the scientific method. Such scholarly presentations ere embodied in the works of Werkmeisler (1996); Obasi (1999); Macionis (1989) and Anikpo (1986). All the scholars identified observation, measurement and quantification, problem identification, hypothesis formulation, experimentation and test of hypothesis, theory construction, and finally, the emergence of law as core element of scientific methods. To what extent this sequence of activities are followed in social science research in general, sociological and policy investigations becomes another issue of great debate among scientists like Rapoport (1969) and the social scientists themselves. It will be pertinent to examine briefly the activities embodied in scientific method as identified above.

Observation: This is simply the act of seeing or watching something happen. By looking at something that is taking place either in an involved capacity or not, makes one an observer. Scientifically, Obasi (1999) defined observation "as a purposeful planned and systematically executed act of watching or looking at the occurrence of events, activities and behaviours which constitute the subject or focus of investigation or study.

Observation is one of the major characteristics of the scientific method. It is through observation that accurate descriptions and explanations of social phenomena can be achieved, and historical trend and social dynamics are recorded and studied. Observation can also generate data which can be used to support or disprove the findings made through other data gathering techniques. Werkmeisler (1996) stated that 
observations signifies a taking note of something seen, heard, felt, tasted, smelled or an irreducible element in our own experience. It is not only noting an event, it also involves the inter-relations in the world around us, it pertains to inferred occurrences and entities no less than to the facts of immediate experience. Since, our senses are not always dependable but may deceive us at critical moments, our own observations must be checked against the observations of others, and, if possible, instruments must be employed, which not only supplement our sense but preserve records of what has occurred, such as telescope and microscope to improve vision. Observation in science exists at two levels, firstly, careful observation as the starting point of investigation, and second, observation as a technique of data collection, Anikpo (1986).

Problem Identification: Careful observation at the commencement of scientific inquiry refers to the appreciation of a problem in the society and the recognition that such problem needs to be systematically investigated. Problematic situations like crime, unemployment and delinquency may necessitate inquiry.

Hypothesis Formulation: Abcarian and Masannat (1970) defined hypothesis as "a proposed explanation of certain events or relationships suggested by past analysis that may be confirmed or refuted by new scientific work. Formulating a hypothesis is a logical step in scientific inquiry which follows the identification of scientific problems. Hypotheses are tentative statements in response to research problems. The importance of hypothesis is to guide the researcher especially in the collection of relevant data.

Experimentation: The idea of conducting an experiment is very crucial to the scientific investigation. In the natural and physical sciences, experiment involved the control of the occurrence of variables under specific conditions in the laboratory. In sociology and policy science, society is the laboratory. The importance of experimentation is to ensure the objectivity of the investigation, which refers to the testability or repeatability. The gathering of empirical data through experiment must follow a sequence which another person can repeat in exactly the same way in case the investigation is in doubt. Experimentation is the sole prove of empiricism of scientific method.

In experiment, stimulus is introduced to the experimental samples, which the investigator finds out if the stimulus has taken the anticipated effect with reference to the earlier formulated hypothesis. This process is referred to as verification or hypothesis testing. This involves the computation of various statistical methods that are made possible by quantification using scales that are relevant to object or subject of the study. Statistical techniques utilized in test of hypothesis such as correlations, chi-square, analysis of variance, t-test, f-test, multiple-regression, etc.

Theory Formulation: Kerlinger (1977) defined theory "as a set of interrelated constructs (concepts), and propositions that presents a systematic view of phenomena by specifying relations among variables, with the purpose of explaining and predicting the phenomena. A theory is the logical conclusion to scientific investigation. It is a declaration of the result of what one had been doing. A theory unlike the hypothesis is verified. It is a rationalisation of the original research problem in such a way that solutions can be applied if necessary. It is the theory that guide practical actions. At this point, it is appropriate to examine the discipline of sociology and its policy dimensions, to see the extent to which the aforementioned sequence in scientific method applied, in order to see if there is anything like the science of sociology as claimed by such eminent sociologists like Auguste Comte (Macionis, 1989).

\subsection{Sociological and Policy Science Methodology}

Reiss, Goldstein, Seabra, Casey, and Brown (1990) defined Sociology as the study of social aggregates and groups in their institutional organisation, of institutions and their organisations, and of the causes and consequences of changes in institutions and social organizations. The central question here is, how scientific is the study of sociology? Sociology is social in content as it focuses on groups, their interaction, relationships, and the roles of individualswithin groups. The units of analysis as identified by Reiss et al. (1990) consists of social system and theirsubsystems; social institutions and structures; social aggregates; relationships; groups; and organizations. Based on its levels of analysis, Rapoport (1969) classified sociology as a non-core science, and posited that all non-core sciences that study human behaviours are social science. Hence sociology qualifies as a social science. But how systematic, and empirical is the sociological methodology in line with accepted scientific procedures and methods?

Like any other social science subject, four fundamental methodologies are clearly identifiable in sociology and policy studies. According to Obasi (1999) there are four major approaches or methods in social sciences, which are: traditionalism; behaviouralism, post-behaviouralism; and Marism. Policy science on the other hand involves the conceptual and methodological analysis of making and implementing decisions and the academic study of the policy process and the solution to social problems, through formulation and implementation of public and social policy. Both sociology and policy science share in the application of scientific methods.

Traditional Method: This method studies sociology and policy from the historical, legalistic, philosophical, normative, descriptive and Institutional perspectives or methods. At the core of traditionalism is the non-preoccupation with observation, verification, quantification and measurement of sociological phenomena. Consequently, the traditional method of sociological investigation is pre-occupied with normative (ethical or moral) issues which are not amenable to observation and measurement. It deals with matters of right and wrong, good and bad, desired and not desired, preferred and not preferred. The issues are heavily 
value-laden, and may not differ from person to person, group to group, institution to institution, community to community, nation to nation. It is this value in traditionalism that makes some scholars like Sorokin to maintain that scientific "sociology is not possible". This method evolved a school of thought in the development of sociology as a discipline. Asexplained by Ritzer (2000) the Traditional school of Methodology in sociology was championed by European trained sociologists like P.A. Sorokin, and Florian Zinaniecki, who argued that sociology is different from biology due to its three components, namely:-

1. Immaterial, speakers and timeless;

2. Material objects that objectify its meanings;

3. Human beings who bear, use and operate these meanings with the help of material objects.

The traditionalists also argued that the cause effect models of traditional science do not apply to sociocultural phenomena, hence socio-cultural science requires special methodology, that of "logico-meaningful causality or integratist method". Ritzer (2000) maintained that sociology differ from other sciences because of the humanistic coefficient and infusion with culturally defined values and meanings. Hence Ritzer prescribed "Analytic induction methodology."

Behaviouralism: This method emerged as an intellectual protest movement within sociology associated mainly with American sociologists. As a protest movement, behaviouralism was dissatisfied with the historical, philosophical, institutional and descriptive methods of conventional social science. It thereafter contended that new methods could be developed to help sociologists formulate empirical propositions and theories of a systematic sort, tested by more direct and more rigorously controlled observations of social events. Behavioural sociology demands that research must be systematic and must place primary emphasis on empirical methods. This method is pre-occupied with the scientific procedures of observation, verification, quantification and measurement. Policy analysis follows also these methods in terms of the adherence to observation, problem identification, identification of alternative solutions, analysis of alternative, comparison of alternative, and selection of most appropriate alternative.

Post-Behaviouralism: Some adherent of the bahaviouralist method got disenchanted with the views of extreme behaviouralists, and softened their positions. Post-behaviouralism emphasizes the need to relate investigation to urgent social problems and was to be purposive. It was the duty of sociology to find out solutions to contemporary societal problems. The following characteristics were laid down for post behavioural investigation.

1. Preference for substance to technique;

2. Emphasis on social change than on social preservation;

3. Emphasis on relevant practical research than on abstract analysis;

4. Recognizes the important role of value as propelling force behind knowledge.

5. Calls on sociologists and policy experts to play active role in shaping the destiny of the society.

6. Calls on social scientists to have a sense of commitment and action by engaging in action science rather than contemplative science.

7. Calls for the socioligisation of the method of science.

Marxism; In the sense of problem solving, post-behaviouralism shares the concerns of Marxism. On the basis of epistemological classification, both traditionalism and behaviouralism are on the side of liberal social science, scholarship, Marxism is on the radical social science and applies scientific method in understanding social phenomena. It draws on the strengths of traditionalism, behaviouralism and post-behaviouralism. It applies historical materialism or dialectical materialism methodology.

From the foregoing discussion, it is clear that only the traditional methodology does not apply the method of science, but behaviouralism post-behaviouralism and Marxism all apply scientific method. But does the utilization in line with the components of scientific method identified earlier in the writings of Werkmeisler (1996); Obasi (1999); Anikpo (1986) and Macionis (1989) make sociology and policy studies sciences? The answer to this question is revealed in the level of application of scientific method in sociological and policy research as highlighted by Macionis (1989). Macionis considered scientific method as a strategy for carrying out research in a systematic way, which is comparable to a blueprint used in building or a pattern used in sewing. Macionis started, with careful observation, problem identification, hypothesis formulation, experimentation, verification, theory formulation, and concluded that all these are applicable in sociology and by extension policy study. Macionis noted that the laboratory base research which are applicable in core (natural and physical sciences) are not applicable in sociological investigation, but what is obtainable in terms of experimentation is survey research, which he considered as a method of sociological investigation in which individuals provide responses to a series of items or questions. It is the most widely used research methodology in sociology and policy study. The main instruments of survey in use in sociology as noted by Macionis (1989) is the questionnaires and interviews. A questionnaire is a series of questions or items to which subjects are asked to respond, while interview involves direct questions administered personally by researcher. The survey technique involves quantification of items using scales depending on the type of variables, such as; Nominal scale, ordinal scale, interval scale, Rational scale, and Fishers protest T-Test (Akpan, 2001). 
Since the population of study is often large, survey also requires studying sample of the population. Data obtained in survey are quantified and analysed statistically to test hypothesis in sociology and policy study. Commonly applied statistical tests in sociology are: correlational statistics, independent T-Test, Dependent TTest, Analysis of variance, chi-square distribution; Historian, Frequency polygon, Line graph, the ogive, Bar Chart, Pie Chart, flow chart, percentage, mean, median, mode, range, mean deviation, standard deviation, coefficient and variation, (Akpan, 2001; Cole, 1980; Nwagbara, 2001; Obasi, 1999; Osuala, 1993).

From the discussion above, it can be concluded that there is a science of sociology and policy studies, because of the application of scientific method in sociological investigation. But if one stops here it is possible to be accused of committing falling of hasty generalization, because there are a lot of impendent to the total utilization of scientific method tools and techniques in sociological investigation.

\section{The Problem of Applying Scientific Method in Sociological and Policy Investigation}

Problems of the scientific status of sociology and policy studies can be classified into two using Anikpo (1986) explanation. First is concern about the objectivity of the researchers' scientific endeavor. This question of objectivity centre on the fact that social phenomena are too complex and in some cases too subjective for any study of the "social" to be objective (scientific). In this regard it is noted that attempts at the scientific study of social phenomena are reductions and distortions of human bahaviour.

The second problem is the methodology which sociology and policy experts adopt to legitimize its claims to scientific status. Obstacle to this is language and faulty measurement. Sociology and policy are full of concepts that are yet too imprecise to be useful in scientific analysis. In the other sciences, most concepts have acquired universal common applicability. In physics for instance, the concept of "motion" as defined by physicists is unlikely to evolve conceptual controversy among them. In sociology for instance, a concept such as "development" will have as varied a meaning as there are sociologists defining it. The attempt to precisely specify its meaning sparks off a barrage of rhetoric which in the end renders the concept scientifically unhelpful.

On faulty measurements, the problem is similar to the first since concepts need precision in order to be effectively measured. It also derives strength from the fact that human beings are difficult to subject to controlled experimentation. Thus Shipman (1991) presents the difficulty thus:

As a social scientist approaches a group or individuals, he becomes part of the situation he is investigating. Part of the behaviour he sees will be a response to his presence. As he tries to understand what goes on in the roads of his subjects, they are interpreting his presence, responding to him, offering him clues to test his response.

Shipman (1991) maintains that unlike the "natural" scientist, who manipulates and controls his experimental objects at will, "the social scientists not only faces humans, who are skilled at wriggling out of controls to establish their own areas of personal freedom, but is himself liable to create new adjustments that destroy the natural situation he is trying to understand.

Macionis (1989) also noted certain limitations of scientific sociology and policy research, which researchers who attempt to study the social world usually encounter, which natural science researchers do not encounter, thus;

1. Since the causes of human behaviour are generally more complex than the causes of natural events, social scientists can only rarely make precise determinations of causes and effect. Thus human behaviour cannot be predicted with the precision of the natural sequences.

2. Sociologists and policy scientists react to the world around them, so the mere presence of sociological investigators may affect the behaviour that the researcher is trying to study. This second point by Macionis equates (Anikpo, 1986) position on faulty measurement.

3. Social patterns vary greatly around the world and are constantly changing; what is true in one place or time may not hold true in another. Atoms and Molecules do not constantly shape their environment; human beings do, in remarkable variable ways. The laws of physics hold anywhere and at any time. Our understanding of human behaviour, however, must acknowledge human diversity and remain subject to revision as ways of life change overtime.

4. Because sociologists and policy analysts are part of the social world they study, objectivity in social research presents special problems. Chemists for example, are not usually affected personally by what goes on in test-tubes; sociologists and policy experts however, live in the society they study. Therefore, sociologists may face greater difficulties in controlling - or even in recognizing - personal values that may distort their work.

Available facts from both Anikpo (1986) and Macionis (1989) proved beyond reasonable doubt that there is limitation to the extent to which scientific method tools and techniques can be applied in sociological and policy investigation. From the words of Rapoport (1969) we cannot have an exact science of sociology, nor policy studies. It is the degree and level of application of scientific methods tools and techniques in a particular discipline, which determines the science or otherwise of that discipline. In view of this realization, what then is 
the future or hope of application of scientific method in sociology and policy studies?

The Prospect of Applying Scientific Method in Sociological and Policy Investigations

The crisis and multiplicity of methodological choice or direction identified in this paper has been one of the major problems affecting the science or development of the science of sociology and policy studies. Scholars who still use traditionalism as methodology are still alien to scientific method in social sciences, but behavioural and Marxist methodological investigators apply scientific methods, tools and techniques at varying degree.

The obstacles identified by both Anikpo (1986) and Macionis (1989) are also gradually wearing off, as sociological theorists and researchers are constantly finding solutions and explanations for their existence. This opened an unending prospect for scientification of sociological and policy investigation.

For instance, Anikpo (1986) noted that social phenomena or human behavior, despite their variability are susceptible to the application of the basic principles of scientific uniformity, which are natural kinds, constancy and deterministic. To this end, Anikpo contended that with appropriate tools, social phenomena, just as Emile Durkheim insisted can be objectively recorded as "social facts" or concrete things, and that to a very large extent, even the most abstract human behavior can be quantified and measured (Ritzer, 2000).

The language problem is equally challenged by social scientists who refused to accept the criticism of language controversy in its entirety. Sociologists contend that conceptual ambiguity is an inherent problem of any newly emerging science. Since both fields have had a shorter history than other sciences, such imprecision in the use of language is expected. It does not by itself nullify the claims of sociology and policy study to scientific status through the application of scientific method.

Sociology and policy studies have problems in the application of scientific method. These problems are certainly not the same today as they were some decades ago. They are also likely to reduce in future. What is important in this transformation is not the enormity of the problems but the importance to human society of a scientific study of sociology and policy studies in particular and social phenomena in general. To study society scientifically is the surest way of controlling the society more effectively.

\subsection{Summary and Conclusion}

This paper provides a detailed analysis of scientific method and expresses the opinion that for any discipline to be considered as a science, investigation in the discipline must utilize scientific methods, tools and techniques of science in their utmost purity in the discovery of knowledge. Sociology and policy studies, which are the main disciplines of focus in this paper deals with human behaviour in group interaction and relationships. Since both disciplines employ the scientific methods in terms of observation, problem identification, empiricism, experimentation quantification, hypothesis formulation and testing through the use of contemporary mathematical and statistical techniques, as well as theory formulation, fit to ascend the status of science. As social sciences, the problem affecting the complete emergence of the science of human behavior acted as limiting factors to the full development of the science of sociology and policy studies, prominent among which are faulty measurement and language problems. In the light of those problems the prospect of full application of scientific method on sociology was also seen.

In conclusion scientific methods are applicable in sociological and policy investigation in line with the limit of the application in other socialsciences. The hope of full application of the method, tools and techniques of science is not in doubt as sociology and policy studies are only two of the newly emerging social sciences, still in its youthfulness as a science.

\section{References}

Abcarian, G., \& Masannat, G. (1970). Contemporary political system. New York: Charles Scribner's Sons.

Adedokun, S. (1999). Theory about theories" unpublished monogaph. Calabar: Department of Political Science, University of Calabar.

Akpan, S. (2001). Principles of research and statistics: An introductory approach. Calabar: Executive Publishers.

Anikpo, M. (1986). Foundations of social research: A methodological guide for students. Enugu: Able Publishers.

Cohen, L., \& Manion, L. (1980). Research methods in education. United Kingdom: Groom Helon.

Cole, R. (1980). Introduction to political inquiry. London: Macmillan Publishing Company.

Ehon, E. C. (1998). Social and economic research: Principles and methods. Lagos: Academic Publications and Development Resources Limited.

Gonser, U., Grant, R. W., Meechan, C. J., Muir, J. A. H., \& Wiedersich, H. (1965). Magnetic transitions in dilute solutions of iron in gold and copper. Journal of Applied Physics, 36(7), 2124-2131. Available at: https://doi.org/10.1063/1.1714431.

Kerlinger, F. (1977). Foundations of behavioural research. New York: Rinehart and Winston.

Macionis, J. (1989). Sociology. New Jersey: Prentice Hall.

Mouly, G. (1978). Educational research: The art and science of investigation. Boston: Allyn and Bacon.

Nwagbara, E. (2001). Doing sociology: The elements of social research. Calabar: Baye Communications.

Obasi, I. (1999). Research methodology in political science. Enugu: Academic Publishing Company.

Osuala, E. (1993). Introduction to research methodology. Onitsha: Africana-Fep Publishers Limited.

Rapoport, F. N. (1969). General system theory, in David Sills (ed.), The International Encyclopedia of Social Sciences (Vol. 14). London: Macmillan. 
Reiss, Y., Goldstein, J. L., Seabra, M. C., Casey, P. J., \& Brown, M. S. (1990). Inhibition of purified p2 1ras farnesyl: Protein transferase by Cys-AAX tetrapeptides. Cell, 62(1), 81-88.

Ritzer, G. (2000). Sociological theory. New York: McGraw-Hill Companies, Inc.

Shipman, D. W. (1991). Method and apparatus for effectively receiving voice input to a voice recognition system: Google Patents.

Werkmeisler, W. (1996). Scientific method, in collier's encyclopedia (Vol. 20). New York: P. P. Collier and Sons Limited.

\section{Bibliography}

Bassey, A.O. (2002). The application of scientific method for sociological investigation. Unpublished Graduate Seminar Paper, Presented as a Requirement of SOC 5402 - Seminar in Advance Sociological Theory, Department of Sociology, University of Calabar, Calabar.

Ezenibe, S. (2001). Lecture on advance sociological theory. Department of Sociology University of Calabar.

Mechan, E. (1965).The theory and method of political science. Homeword III: The Dorsey Press.

Ndiyo, A. A. (2005). Fundamentals of research in behavioural sciences and humanities. Calabar: Wusen Press.

Reiss, A. (1990). The field of sociology, in David Sills (ed.) The international encyclopedia of social sciences. London: Macmillan, 15.

Shipman, M. (1991).The limitations of social research. London: Longman.

Udo, E. (1993).Philosophy without tears: A first reader in Philosophy. Uyo: Modern Business Press Limited. 